\title{
Melanin-concentrating hormone: a new sleep factor?
}

\author{
Pablo Torterolo ${ }^{1}$, Patricia Lagos ${ }^{1}$ and Jaime M. Monti ${ }^{2 *}$ \\ ${ }^{1}$ Department of Physiology, School of Medicine, University of the Republic, Montevideo, Uruguay \\ 2 Department of Pharmacology and Therapeutics, School of Medicine, Clinics Hospital, Montevideo, Uruguay
}

\section{Edited by:}

Michael J. Thorpy, Albert Einstein

College of Medicine of Yeshiva

University, USA

Reviewed by:

John J. Renger, Merck Research Laboratories, USA

Priyattam J. Shiromani, Harvard

Medical School, USA

\section{${ }^{*}$ Correspondence}

Jaime M. Monti, Department of Pharmacology and Therapeutics, School of Medicine, Clinics Hospital Montevideo 11600, Uruguay. e-mail: jmonti@mednet.org.uy

\begin{abstract}
Neurons containing the neuropeptide melanin-concentrating hormone $(\mathrm{MCH})$ are mainly located in the lateral hypothalamus and the incerto-hypothalamic area, and have widespread projections throughout the brain. While the biological functions of this neuropeptide are exerted in humans through two metabotropic receptors, the MCHR1 and MCHR2, only the MCHR1 is present in rodents. Recently, it has been shown that the MCHergic system is involved in the control of sleep. We can summarize the experimental findings as follows: (1) The areas related to the control of sleep and wakefulness have a high density of MCHergic fibers and receptors. (2) MCHergic neurons are active during sleep, especially during rapid eye movement (REM) sleep. (3) $\mathrm{MCH}$ knockout mice have less REM sleep, notably under conditions of negative energy balance. Animals with genetically inactivated MCHR1 also exhibit altered vigilance state architecture and sleep homeostasis. (4) Systemically administered MCHR1 antagonists reduce sleep. (5) Intraventricular microinjection of $\mathrm{MCH}$ increases both slow wave sleep (SWS) and REM sleep; however, the increment in REM sleep is more pronounced. (6) Microinjection of $\mathrm{MCH}$ into the dorsal raphe nucleus increases REM sleep time. REM seep is inhibited by immunoneutralization of $\mathrm{MCH}$ within this nucleus. (7) Microinjection of $\mathrm{MCH}$ in the nucleus pontis oralis of the cat enhances REM sleep time and reduces REM sleep latency. All these data strongly suggest that $\mathrm{MCH}$ has a potent role in the promotion of sleep. Although both SWS and REM sleep are facilitated by $\mathrm{MCH}$, REM sleep seems to be more sensitive to $\mathrm{MCH}$ modulation.
\end{abstract}

Keywords: hypothalamus, depression, raphe nuclei, orexin, peptides, REM sleep

\section{INTRODUCTION}

Sleep occupies approximately one-third of human's life. Sleep is not a homogeneous process. In most mammals two sleep states are recognized: slow wave sleep (SWS) and the rapid eye movements (REM) sleep. Wakefulness, SWS, and REM sleep are differentiated by the electroencephalographic (EEG) activity (synchronized during SWS, desynchronized during wakefulness, and REM sleep), cognition (consciousness during wakefulness and dreams during REM sleep), muscle activity (atonia during REM sleep), and others physiological parameters (McCarley, 2007; Torterolo and Vanini, 2010).

In the twentieth century experimental and clinical research began to unravel the mystery of sleep. Nowadays, the main neuronal networks that are involved in the generation of wakefulness, SWS, and REM sleep are known (Siegel, 2005; McCarley, 2007; Szymusiak and McGinty, 2008; Torterolo and Vanini, 2010). The thalamo-cortical network is the pacemaker for the EEG rhythms of wakefulness and sleep, and is the scaffold for the cognitive functions. This network is regulated by the activating (wakingrelated) systems located in the basal forebrain, postero-lateral hypothalamus, and mesopontine reticular formation. While the preoptic area is critical for SWS generation, the mesopontine region contains the "necessary and sufficient" neuronal networks for REM sleep generation.
Several neurotransmitters and neuromodulators such as acetylcholine (ACh), noradrenaline (NA), dopamine, serotonin, histamine, adenosine, and hypocretins, have been involved in the control of sleep and wakefulness (Jones, 2005; McCarley, 2007; Torterolo and Vanini, 2010). Do melanin-concentrating hormone $(\mathrm{MCH})$, and MCHergic system play a role in the control of sleep? Is $\mathrm{MCH}$ a sleep factor? So far, about 1000 papers related to $\mathrm{MCH}$ have been published. Notwithstanding this, only a relatively small number of publications associate $\mathrm{MCH}$ with sleep. In this review article we evaluate the data on $\mathrm{MCH}$ and sleep, and give our point of view of how the MCHergic system might regulate behavioral states.

\section{MELANIN-CONCENTRATING HORMONE}

In mammals, MCH is a cyclic neuropeptide with 19 aminoacids that has been found predominantly in neurons localized in the lateral hypothalamus and incerto-hypothalamic area (Kawauchi et al., 1983; Skofitsch et al., 1985; Bittencourt et al., 1992).

Originally, $\mathrm{MCH}$ was described as a circulating hormone isolated from salmon pituitaries, where it induces the aggregation of melanin granules in melanophores; this action results in a pale skin color (Kawauchi et al., 1983). This mechanism lets the animal to camouflage in response to the background color of the environment or in response to stress. This effect is opposite to 
the pigment-dispersing effect of alpha-melanocyte stimulating hormone ( $\alpha-\mathrm{MSH})$. Subsequently, $\mathrm{MCH}$ was identified in rat brain using immunohistochemical techniques (Skofitsch et al., 1985; Bittencourt et al., 1992).

$\mathrm{MCH}$ structure is identical in all mammals analyzed to date, including mice, rats, rabbits, and humans (Saito and Nagasaki, 2008). $\mathrm{MCH}$ is generated by the cleavage of a precursor of 165 amino acids, the prepro- $\mathrm{MCH}$ (ppMCH). ppMCH contains other peptides in addition to $\mathrm{MCH}$, designated as neuropeptide EI (NEI) and neuropeptide GE (NGE; Bittencourt and Celis, 2008). In addition, the precursor may potentially give rise to an alternative splice variant termed $\mathrm{MCH}$-gene-overprintedpolypeptide (MGOP), as well as a portion of the antisense-RNAoverlapping-MCH (AROM; Toumaniantz et al., 1996; Borsu et al., 2000).

\section{MCH RECEPTORS AND SIGNALING MECHANISMS}

Several research groups almost simultaneously discovered the first $\mathrm{MCH}$ receptor in 1999. It was found to be an orphan G-protein coupled receptor, named SLC-1 (Bachner et al., 1999; Chambers et al., 1999; Lembo et al., 1999; Shimomura et al., 1999). Because $\mathrm{MCH}$ was the only ligand from rat brain extract that activated rat or human SLC-1 receptor, it was named MCHR1. In 2001, another $\mathrm{MCH}$ receptor was identified. This receptor was termed MCHR2 and has a 38\% sequence homology with MCHR1 (Hill et al., 2001; Mori et al., 2001; Sailer et al., 2001). The binding of $\mathrm{MCH}$ to MCHR1 activates diverse intracellular signaling pathways by coupling to $\mathrm{Gi}, \mathrm{Gq}$, and Go proteins, while MCHR2 is known to couple to the Gq protein (Hawes et al., 2000; Sailer et al., 2001).

\section{ANATOMY OF THE MCHergic SYSTEM LOCATION OF THE MCHergic NEURONS}

In their classical paper Bittencourt et al. (1992) described that the ppMCH mRNA as well as $\mathrm{MCH}$ were localized in neurons of the lateral hypothalamic area, and the incerto-hypothalamic area of the rat. MCHergic neurons are distributed continuously in a rostrocaudal extent approximately from the level of the caudal aspect of the paraventricular nucleus to just beyond the mammillary recess in rat, cats, and humans (Bittencourt et al., 1992; Mouri et al., 1993; Torterolo et al., 2006). Photomicrographs of the MCHergic neurons in the tuberal hypothalamic region of the cat are shown in Figure 1.

A small number of $\mathrm{MCH}$-containing neurons was also observed in the olfactory tubercle and pontine reticular formation in the rat, as well as in the laterodorsal tegmental (LDT) nucleus and preoptic area of female and lactating rats, respectively (Bittencourt et al., 1992; Rondini et al., 2007, 2010).

\section{PROJECTIONS OF THE MCHergic NEURONS}

MCHergic neurons project widely throughout the central nervous system (CNS; Bittencourt et al., 1992). Because of their importance in the control of the sleep-wake cycle, we highlight the projections toward the thalamus, the tubero-mammillar nucleus of the hypothalamus, the preoptic area of the hypothalamus, the ventral tegmental area, the periaqueductal gray, the locus coeruleus (LC), the nucleus pontis oralis (NPO), the laterodorsal
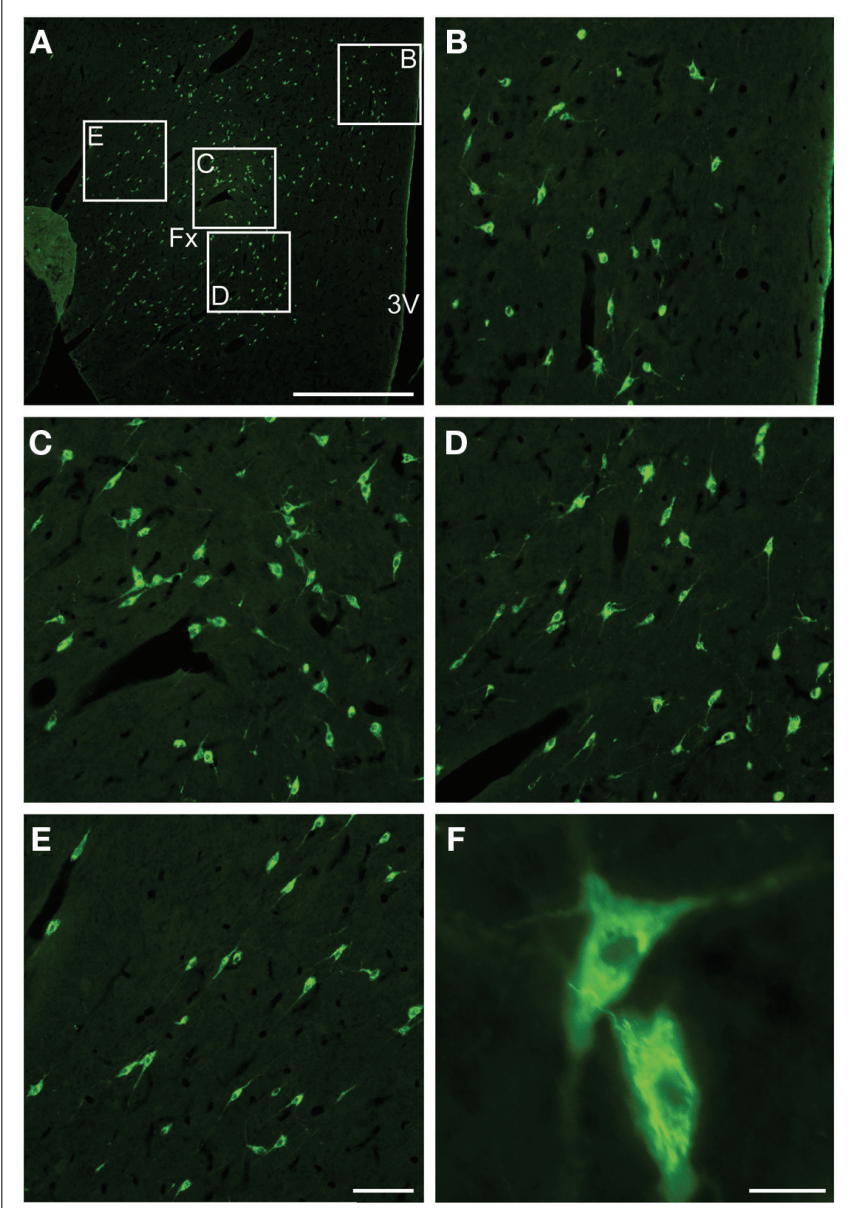

FIGURE 1 | MCHergic neurons are located in the hypothalamus of the cat. (A) Low magnification photomicrographs that exhibit $\mathrm{MCHergic}$ neurons at the tuberal level of the hypothalamus. (B-E) The insets in (A) are shown at higher magnification. These photomicrographs show $\mathrm{MCHergic}$ neurons of the dorsal hypothalamic area (B), the perifornical region (C,D), and the lateral hypothalamic area (E). (F) Two MCHergic neurons are shown at high magnification. The photomicrographs were taken from $20-\mu \mathrm{m}$-thick sections that were processed for immunofluorescence. FITC was used as fluorescent agent. Fx, fornix; 3V, third ventricle. Calibration bars: (A) $1 \mathrm{~mm}$; (B-E) $100 \mu \mathrm{m}$; (F) $20 \mu \mathrm{m}$. This figure was modified from Torterolo et al. (2006).

and pedunculopontine tegmental (LDT-PPT) nuclei, and the dorsal raphe (DR) nucleus. Furthermore, projections to other structures such as the cerebral cortex, amygdala, and motor nuclei have been described (Bittencourt et al., 1992; McGregor et al., 2005; Elias et al., 2008; Torterolo et al., 2009).

\section{DISTRIBUTION OF THE MCH RECEPTORS}

$\mathrm{MCH}$ receptors are distributed in diverse areas of the CNS. The MCHR1 is present in all mammals studied to date, while the MCHR2 is functional in dogs, ferret, rhesus monkey, and humans but is a pseudogene in rodents (Tan et al., 2002).

There is a widespread distribution of the MCHR1 mRNA, and like the MCHergic fibers, this receptor is present in limbic 
structures and in areas related to the control of sleep and wakefulness. MCHR1 have been detected also in several peripheral organs (Chung et al., 2009).

The distribution of MCHR2 nearly overlaps with that of MCH1R, but the latter shows higher relative levels of density and a wider distribution pattern (Hill et al., 2001; Mori et al., 2001). The function of MCHR2 remains unknown due to the lack of available animal models.

\section{MCH: VOLUME CONDUCTION THROUGH THE CEREBROSPINAL FLUID (CSF)?}

As it is the case with the central actions of oxytocin (Veening et al., 2010), it is likely that some of its biological effects are produced by volume conduction, through a neuro-humoral pathway via the CSF (Torterolo et al., 2008). In a recent report, Veening and Barendregt (2010) stated that the CSF system, in addition to provide nutrients to and remove waste products from the brain, contains message molecules in the form of actively released neuroactive substances. The authors suggested that this special form of volume transmission is a way to broadcast coordinated messages to a variety of brain areas and may underlay changes in behavioral states (Veening and Barendregt, 2010).

MCHergic fibers are lying close the ventricle walls of the cat (P. Torterolo, unpublished observation) and $\mathrm{MCH}$ is present in the CSF (Quintela et al., 2010). At the level of the DR, we demonstrated that tanycytes lining the floor of the fourth ventricle show positive immunoreactivity for $\mathrm{MCH}$, and that their long basal processes are closely related to serotonergic neurons of the DR (Torterolo et al., 2008). The tanycytes are specialized ependymal cells that uptake substances from the CSF and release them to the underlying neuropil (Rodriguez et al., 2005). Since serotonergic neurons of the DR have a fundamental role in the control of REM sleep (Monti, 2010a, 2010b), MCH could modulate the serotonergic activity and REM sleep through this type of volume conduction (see below).

\section{MCHergic SYSTEM. FUNCTIONAL CONSIDERATIONS NEUROTRANSMITTERS THAT CO-LOCALIZE WITH MCH}

In addition to the neuropeptides derived from the ppMCH, other neurotransmitter and neuromodulators have been described to co-localize with MCH. Elias et al. (2001) have demonstrated that the anorexinergic cocaine- and amphetamine-regulated transcript (CART), is co-expressed in 95\% of the MCHergic neurons of the zona incerta and in $70 \%$ of $\mathrm{MCH}$-positive neurons of the lateral hypothalamus of the rat. MCHergic neurons that co-localize with CART send ascending projections toward the septum and hippocampus, whereas the non-CART MCHergic neurons send descending projections toward the brainstem and spinal cord (Hanriot et al., 2007). In addition, all the MCHergic neurons express the novel hypothalamic molecule nesfatin-1 that also suppresses feeding (Fort et al., 2008).

Recently, utilizing $\mathrm{MCH}$ immunohistochemistry and in situ hybridization to detect GAD67 mRNA, Sapin et al. (2010) demonstrated that $85 \%$ of the MCHergic neurons of the tuberal region of the hypothalamus are also GABAergic. Besides, $\mathrm{MCH}$ and GABA co-localize in the LDT and medial preoptic area (Rondini et al., 2007, 2010).

\section{ELECTROPHYSIOLOGICAL CHARACTERISTIC OF THE MCHergic NEURONS}

In vitro recordings have shown that the MCHergic neurons present a resting potential ranging from -62 to $-50 \mathrm{mV}$, slightly more hyperpolarized than nearby hypocretinergic neurons (Guyon et al., 2009). MCHergic neurons also showed a relatively low level of spontaneous activity compared with hypocretinergic and GABAergic neurons of the region.

Glutamate and GABA regulate MCHergic neuronal activity. Accordingly, both AMPA and NMDA depolarize these neurons (van den Pol et al., 2004). The activation of group I of metabotropic glutamate receptors also excite MCHergic neurons (Huang and van den Pol, 2007). The GABA agonist muscimol hyperpolarizes MCHergic neurons while there are no data regarding the effect of GABA $\mathrm{B}$ agents Guyon et al. (2009).

\section{SYNAPTIC EFFECTS OF MCH}

Studies in lateral hypothalamic neurons in vitro have shown a predominantly inhibitory effect of $\mathrm{MCH}$ both at pre- and postsynaptic levels (Gao and van den Pol, 2001). Hence, MCH inhibited the synaptic activity of both glutamatergic and GABAergic inputs to lateral hypothalamic neurons. In addition, $\mathrm{MCH}$ reduced the amplitude of glutamate-evoked currents and the amplitude of miniature excitatory currents, indicating an inhibitory modulation of postsynaptic glutamate receptors. Furthermore, $\mathrm{MCH}$ attenuated L-, N-, and P/Q-type calcium of calcium voltageactivated currents (Gao and van den Pol, 2002).

MCHergic neurons express MCHR1 autoreceptors; by this mean the neuropeptide inhibits MCHergic neurons via a depression of voltage-dependent calcium channels without affecting the resting potential (Huang et al., 2007). Therefore, MCHergic neurons would exert a negative feedback on their own activity.

\section{ROLE OF MCH IN THE CONTROL OF ENERGY HOMEOSTASIS AND MOOD}

The high conservation of $\mathrm{MCH}$ structure along phylogeny suggests that this neuropeptide is involved in important physiological processes. The lateral hypothalamic area, where the MCHergic neurons are mainly located, is an integrative region par excellence. This region has been implicated in a wide variety of functions, such as energy homeostasis, wakefulness and sleep, regulation of motor activity, motivation, and reward (Bernardis and Bellinger, 1996). MCHergic neurons seem to be implicated in some of these functions.

Due to the strong relationship among sleep, energy homeostasis and major depression we will briefly review the role of $\mathrm{MCH}$ in these processes and condition.

There are strong experimental evidences that $\mathrm{MCH}$ increases food intake and reduces energy expenditure such as:

1. Acute infusion of $\mathrm{MCH}$ into the lateral ventricles induces feeding in rodents. Fasting induces an up-regulation of $\mathrm{MCH}$ mRNA expression (Qu et al., 1996).

2. MCH mRNA levels are also elevated in the obese leptindeficient ob/ob mice, suggesting that leptin negatively regulates MCH expression (Qu et al., 1996). In fact, by means of double knockout mice for $\mathrm{MCH}$ and leptin, it was demonstrated that 
$\mathrm{MCH}$ is a critical mediator of the leptin-deficient phenotype (Segal-Lieberman et al., 2003).

3. The stimulating effect of food intake has been confirmed in transgenic mice, in which an over-expression of $\mathrm{MCH}$ causes obesity (Ludwig et al., 2001), while prepro-MCH knockout mice (MCH-KO) are hypophagic and lean (Shimada et al., 1998). Indeed, MCH is the only known hypothalamic peptide whose genetic deletion results in leanness. In these $\mathrm{MCH}-\mathrm{KO}$ mice, an increase in temperature, heart rate, and metabolic rate occurs along with an increase in energy expenditure (Astrand et al., 2004). A toxin-mediated genetic cell ablation strategy using a truncated ataxin-3 has been applied to induce apoptosis of MCHergic neurons; these mice developed a late onset syndrome characterized also by leanness, hypophagia, and increased energy expenditure (Alon and Friedman, 2006).

4. Mice knockout for the MCHR1 are lean, although in contrast to $\mathrm{MCH}-\mathrm{KO}$ mice, they are hyperactive, hyperphagic, and have altered metabolism (Marsh et al., 2002). In addition, blockade of MCHR1 with specific antagonists has anorectic effects (Borowsky et al., 2002).

5. The MCHergic neurons are under the direct control of NPYcontaining neurons of the arcuate nucleus; these neurons are part of the neuronal network that governs feeding and energy expenditure (van den Pol et al., 2004). Furthermore, peripheral signals of energy abundance such as glucose, enhance MCHergic activity in vitro (Burdakov et al., 2005).

The presence of MCHergic fibers and receptors in the limbic system tends to suggest that the MCHergic system plays a role in the control of mood and emotion. Borowsky et al. (2002) have showed that systemic administration of an MCHR1 antagonist produces antidepressant effects (Borowsky et al., 2002). We have also shown that the microinjection of a low dose of $\mathrm{MCH}$ ( $50 \mathrm{ng}$ ) into the DR of the rat evokes a depressive-like behavior as shown by a significant increase in the immobility time as well as a decrease in climbing behavior in the forced swimming test (Lagos et al., 2011b). The depressive-like effect induced by $\mathrm{MCH}$ was prevented by systemic pre-treatment with fluoxetine, a selective serotonin reuptake inhibitor. Consistent with these results, the immunoneutralization of $\mathrm{MCH}$ by microinjection of antibodies anti-MCH into the DR has antidepressant effects; anti-MCH antibodies decreased the immobility time in the forced swimming test without modifying the motor activity measured in the open field test.

The above-mentioned data suggest that $\mathrm{MCH}$ modulates the activity of serotonergic DR neurons, and could be involved in the control of mood. Furthermore, antagonism of the MCHR1 produces also a decrease in anxiety in animals models (Borowsky et al., 2002; Chaki et al., 2005).

Additional functions of MCH via central or peripheral MCHR1 such as the control of reproduction or the immune response have been also described (Lakaye et al., 2009; Wu et al., 2009).

\section{ROLE OF MCH IN THE CONTROL OF SLEEP AND WAKEFULNESS}

From 2003 on, several investigators have examined the role of $\mathrm{MCH}$ in sleep, and the evidence indicates that it pro- motes sleep (Torterolo et al., 2003a; Verret et al., 2003; Willie et al., 2003).

\section{ANATOMICAL CONSIDERATIONS}

We mentioned above that MCHergic fibers and receptors are present in regions related to the control of sleep and wakefulness. In addition, MCHergic neurons have been identified in key areas responsible for the generation of wakefulness and REM sleep such as the LDT (only in female rats), and the pontine reticular formation (Bittencourt et al., 1992; Rondini et al., 2007). Last but not least, $\mathrm{MCH}$ is present in the tanycytes of the DR of the cat, where serotonergic REM “OFF” neurons are present (Torterolo et al., 2008).

\section{RELATIONSHIP WITH HYPOCRETINERGIC NEURONS}

Due to the importance of the hypocretinergic system in sleep physiology and pathology, the interaction between the MCHergic, and the hypocretinergic system is worth to be considered. The hypocretinergic neurons degenerate in narcolepsy, a paradigmatic sleep disorder (Nishino et al., 2000; Peyron et al., 2000; Thannickal et al., 2000). The activity of the hypocretinergic neurons increases during active wakefulness, and they are believed to be central in the maintenance of this state (Torterolo et al., 2001, 2003b; Lee et al., 2005; Mileykovskiy et al., 2005).

A strong relationship exists between hypocretinergic and MCHergic neurons in the hypothalamus. The MCHergic neurons are intermingled with hypocretin (also called orexin)-containing neurons in the lateral hypothalamus, mainly at the tuberal and tubero-mammillar levels (Torterolo et al., 2006). MCHergic fibers are in close relationship with hypocretinergic neurons and vice versa, which tends to indicate the existence of reciprocal synaptic contacts between both types of cells (Guan et al., 2002; Torterolo et al., 2006). This fact as well as the presence of hypocretinergic receptors on MCHergic neurons suggests an important functional interaction between both systems (Backberg et al., 2002). In fact, hypocretin increases $\mathrm{MCH}$ mRNA expression in hypothalamic neurons, directly excites MCHergic neurons and increases glutamate release onto them (Bayer et al., 2002; van den Pol et al., 2004). On the other hand, MCH modulates hypocretin/orexinmediated effects on behavioral state and synaptic transmission in the lateral hypothalamus (Rao et al., 2008). Rao et al. (2008) demonstrated that the efficacy of glutamatergic synapses on hypocretinergic neurons is enhanced in MCHR1 knockout mice, and hypocretin-1-induced firing is facilitated. On the contrary, in wild-type mice, $\mathrm{MCH}$ significantly attenuated the hypocretin1 -induced enhancement of spike frequency in hypocretinergic neurons, but not its basal activity. Furthermore, in these neurons, $\mathrm{MCH}$ attenuated hypocretin-1-induced enhancement of the frequency of miniature excitatory postsynaptic currents (EPSCs). These effects imply that $\mathrm{MCH}$ exerts a unique inhibitory influence on hypocretinergic signaling as a way to fine-tune the output of these neurons.

Interestingly, hypocretinergic and $\mathrm{MCHergic}$ neurons respond in a different way to most homeostatic signals such as glucose (Burdakov et al., 2005), or to waking-related neurotransmitters such as NA (Bayer et al., 2005). In this regard, it is of note that while hypocretinergic neurons express the $\alpha 1$ adrenergic receptors, 
MCHergic neurons express the $\alpha 2$ adrenergic receptors, which are related to activation or inhibition of its target, respectively (Modirrousta et al., 2005).

\section{WAKING AND SLEEP-RELATED MECHANISMS NEUROTRANSMITTERS REGULATE MCHergic ACTIVITY}

Serotonergic neurons of the dorsal and median raphe nucleus, as well as noradrenergic neurons of the LC are active during wakefulness (Monti and Jantos, 2008; Monti, 2010b; Torterolo and Vanini, 2010). Midbrain dopaminergic neurons are also involved in the promotion of wakefulness (Monti and Jantos, 2008). On the other hand, cholinergic neurons are active both during wakefulness and REM sleep (Torterolo and Vanini, 2010). All these neurotransmitters regulate the activity of the MCHergic neurons.

Noradrenaline hyperpolarizes the MCHergic neurons by direct synaptic actions mediated by the $\alpha 2$ adrenergic receptor (van den Pol et al., 2004). Furthermore NA has presynaptic effects; it decreases the frequency of EPSCs and increases the frequency of miniature inhibitory postsynaptic currents (IPSCs; van den Pol et al., 2004).

Serotonin hyperpolarizes MCHergic neurons in the presence of TTX indicating a direct postsynaptic effect (van den Pol et al., 2004).

Dopamine decreases the excitability of MCHergic neurons by decreasing the membrane resistance without modifying the resting potential (Guyon et al., 2009).

Acetylcholine hyperpolarizes MCHergic neurons through muscarinic receptors and increases GABA release onto these neurons through nicotinic mechanisms (van den Pol et al., 2004).

Cannabinoids are sleep-promoting neuromodulators (MurilloRodriguez, 2008), and they increase the firing rate of the MCHergic neurons. Acting through the CB1 receptor, these substances induce depolarization of MCHergic neurons and decrease the activity of nearby GABAergic neurons (Huang et al., 2007).

In summary, extrahypothalamic waking-related neurotransmitters (NA, serotonin, ACh) inhibit MCHergic neurons, thus suggesting that in order to generate or maintain wakefulness, these neurons should be inhibited. Notwithstanding this, it is intriguing that ACh promotes REM sleep and simultaneously inhibits MCHergic neurons (see below).

\section{MCHergic NEURONAL ACTIVITY DURING WAKEFULNESS AND SLEEP}

Harthoorn et al. (2005) have demonstrated an up-regulation of the content of $\mathrm{MCH}$ in hypothalamic neurons during the resting phase of the light-dark cycle of the rat, when this animal sleeps more.

Modirrousta et al. (2005), studied the $c$-fos expression (as an index of neuronal activity) of the MCHergic neurons after a sleep rebound that followed a short protocol $(3 \mathrm{~h})$ of total sleep deprivation in the rat. Although $c$-fos expression was observed in a very small proportion of MCHergic neurons $(\approx 3 \%)$, the authors demonstrated that MCHergic neurons were activated during the sleep rebound (that consisted mainly in SWS) in comparison to wakefulness. In contrast, almost no MCHergic neurons expressed $c$-fos during sleep (mainly SWS) induced by an adenosine receptor agonist in rats (Satoh et al., 2006). In the cat, we did not observe Fos immunoreactivity in MCHergic neurons either during a SWS rebound that followed a short protocol of total sleep deprivation, or during REM sleep induced by microinjections of carbachol into the NPO (Torterolo et al., 2006). However, it should be considered that the occurrence of a false negative is one of the inconveniences of this technique.

Verret et al. (2003) also studied the $c$-fos expression in the MCHergic neurons of the rat during a REM sleep rebound that followed a prolonged protocol (72 h) of REM sleep deprivation. The authors observed that in comparison to the waking period, during the REM sleep rebound a large number of Fos+ cells were immunoreactive for $\mathrm{MCH}$ and almost $60 \%$ of the $\mathrm{MCH}$ containing neurons were Fos positive. The MCHergic neurons that expressed $c$-fos either did or did not co-localize CART (Hanriot et al., 2007).

In accordance with the studies mentioned above, MCHergic neurons did not express $c$-fos in wakefulness induced by application of $\mathrm{GABA}_{\mathrm{A}}$ antagonists in the lateral hypothalamus (Goutagny et al., 2005).

Hassani et al. (2009) made use of in vivo extracellular recordings of identified MCHergic neurons of head restrained rats to describe their activity during the sleep-wakefulness cycle. These neurons were silent during wakefulness and began to discharge during the SWS transition; their firing rate slightly increased during SWS and reached a maximum during REM sleep. During this period of time they fired in doublets or groups of spikes, and often in relation to twitches of the whiskers and muzzle. Furthermore, the MCHergic neurons discharged in a reciprocal manner to the hypocretinergic neurons. Although the sleep "ON" pattern of discharge of the neurons that were analyzed was clear, it remains to know if this is the general pattern of activity of all the hypothalamic and extrahypothalamic MCHergic neurons. Besides, due to the strong relationship of the MCHergic neurons with the control of energy homeostasis, it would be important to know if in conditions of positive energy balance there are MCHergic neurons active during wakefulness, as suggested by the in vitro studies of Burdakov et al. (2005).

\section{STUDIES ON GENETICALLY MODIFIED MICE}

Studies in knockout mice for both MCHR1 and $\mathrm{MCH}$, show that these animals have an altered sleep architecture (Adamantidis et al., 2008; Willie et al., 2008).

$\mathrm{MCH}-\mathrm{KO}$ mice have a reduction in SWS and an increase of wakefulness during baseline conditions (Willie et al., 2008). In response to fasting these animals exhibit a marked hyperactivity, accelerated weight loss, and an exaggerated decrease in REM sleep compared to the wild-type littermates. The decrease in REM sleep results from a reduced number of REM sleep bouts. Following $6 \mathrm{~h}$ of sleep deprivation, these animals have a normal sleep rebound. This data support a role for $\mathrm{MCH}$ in vigilance state regulation, particularly in response to a challenge in energy homeostasis.

Adamantidis et al. (2008) studied the spontaneous sleep and its homeostatic regulation in mice with deletion of the MCHR1 gene. In contrast to previous data showing that $\mathrm{MCH}$ promotes sleep, the authors described that the lack of functional MCHR1 results in a hypersomnia-like phenotype. In comparison with wild littermates, these mice exhibit higher amounts of REM sleep during the active (dark) phase. Furthermore MCHR-1 knockout mice 
showed a more pronounced rebound of SWS in response to sleep deprivation. In addition, the authors found that modafinil, a stimulating drug, induced less wakefulness in MCHR1 knockout mice than in wild-type littermates. Then, these MCHR1 knockout animals exhibit altered vigilance and sleep homeostasis, but the sign of the alteration seems the opposite to previous results. The authors discussed that these unexpected results could be related to the development of compensatory mechanisms; the resulting adaptive changes would oppose those caused by the blockade of the endogenous peptide.

\section{EFFECT OF MCH ADMINISTRATION ON SLEEP VARIABLES Intraventricular microinjections of $\mathrm{MCH}$}

Intraventricular microinjections of $\mathrm{MCH}$ into the active (dark) phase of the rat, produced a marked increase in REM sleep (up to $200 \%$ above control values) and a moderate increase in SWS (up to $70 \%$ of control values; Verret et al., 2003). The increment in REM sleep time was due to an increase in the frequency of REM sleep episodes, whereas their duration remained unchanged.

\section{Intracerebral microinjections of $\mathbf{M C H}$}

Using cholera toxin subunit-b as a retrograde tracer in cats, we have demonstrated that $\approx 15 \%$ of the lateral hypothalamic neurons that project to the NPO, contained MCH (Torterolo et al., 2009). The NPO of the cat (also called medial pontine reticular formation or perilocus coeruleus $\alpha$ ) or its corresponding nucleus in the rat, which is called the sub-laterodorsal nucleus, is an integral part of different models of REM sleep, and is considered to exert executive control over the initiation and maintenance of this behavioral state (Reinoso-Suarez et al., 2001; Xi et al., 2001; Chase and Morales, 2005; Siegel, 2005; Fuller et al., 2007; Luppi et al., 2007; McCarley, 2007). A single injection of a cholinergic agonist, such as carbachol, generates REM sleep with a very short latency (down to $30 \mathrm{~s}$ ) and a duration that can exceed $2 \mathrm{~h}$ (Baghdoyan et al., 1987). Microinjections of $\mathrm{MCH}$ within this region produced a significant decrease in REM sleep latency with an increase in the time the animal spent in this behavioral state. The increment in REM sleep time was due to a increase of REM sleep episodes duration and frequency (Torterolo et al., 2009).

As mentioned earlier, the DR has a dense network of $\mathrm{MCH}$ immunoreactive fibers and tanycytes (Torterolo et al., 2008). In this respect, we have studied the effect of $\mathrm{MCH}$ administration into the DR on sleep during the light period of the light-dark cycle of the rat. $\mathrm{MCH}$ induced a marked and dose-dependent increase of the time the animal spent in REM sleep, and also a moderate increase of SWS; on the other hand, wakefulness was reduced (Lagos et al., 2009). The increase of REM sleep time was due to an increment in the frequency of REM sleep bouts, while the duration of the episodes was not modified. Figure 2 shows representative hypnograms of an animal microinjected with $\mathrm{MCH}$ or vehicle (control) into the DR.

The blockade of physiologically released-MCH in the DR by immunoneutralization (microinjections of antibodies anti-MCH) increased wakefulness and suppressed REM sleep, while SWS tended to remain unchanged (Lagos et al., 2011a). The decrement in REM sleep time was due to a decrease in the frequency of
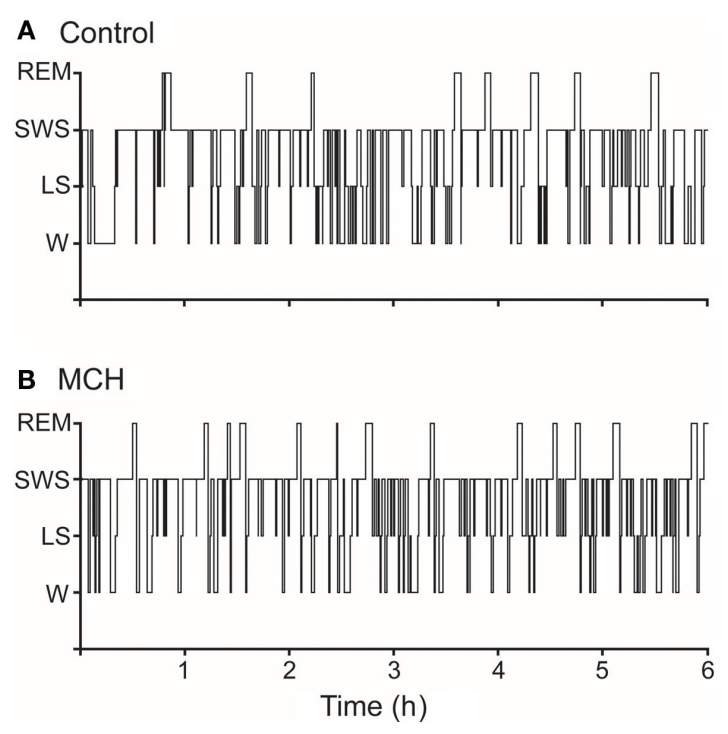

FIGURE 2 | Representative hypnograms illustrating the occurrence of wakefulness and sleep following microinjection of $\mathrm{MCH}$ into the dorsal raphe nucleus. The effects of the vehicle (A), and $100 \mathrm{ng}$ of $\mathrm{MCH}$ (B) are presented. Comparing to control, the hypnogram corresponding $\mathrm{MCH}$ microinjection depicts a substantial increase in the number of REM sleep episodes. This figure was modified from Lagos et al. (2009).
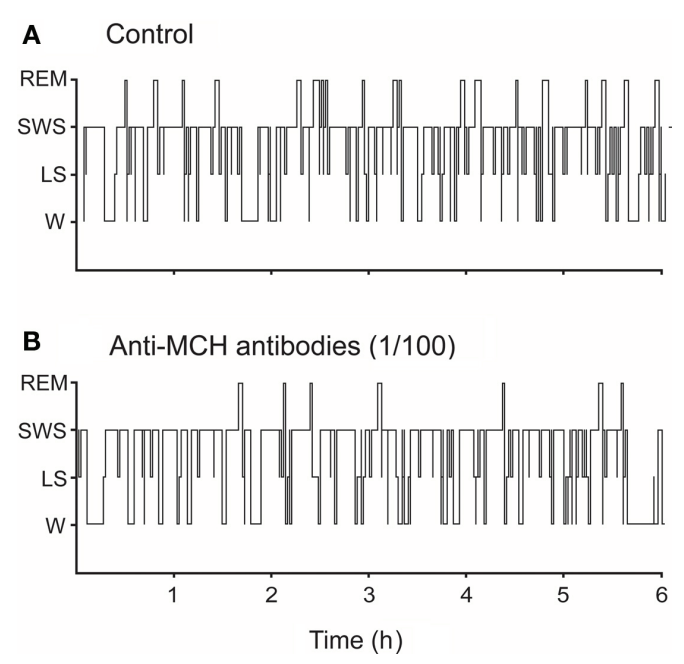

FIGURE 3 | Representative hypnograms illustrating the occurrence of wakefulness and sleep following microinjection of anti-MCH antibodies (immunoneutralization) into the dorsal raphe nucleus. The effects of the vehicle $(\mathbf{A})$ and $1 / 100$ dilution dose of anti-MCH (B) are presented. Comparing to control, the hypnogram corresponding to anti-MCH microinjection depicts a substantial decrease in the number of REM sleep episodes. This figure was modified from Lagos et al. (2011a).

REM sleep episodes whereas the duration of the episodes was not modified (Figure 3).

\section{Systemic administration of MCHR1 antagonists}

Systemic administration of MCHR1 antagonists in rats decreased SWS and REM sleep time. This treatment also increased 
wakefulness as well as SWS and REM sleep latencies (Ahnaou et al., 2008). The reduction of REM sleep was related to a smaller number of REM sleep bouts, while the duration of the REM sleep episodes was unchanged.

\section{MCH: PROMOTION OF SLEEP AND SUPPRESSION OF WAKEFULNESS}

Most of the preceding data strongly suggest that the MCHergic system promotes sleep, but especially REM sleep. Indeed, reversible inactivation by microinjection of a $\mathrm{GABA}_{\mathrm{A}}$ agonist into the hypothalamic area where the MCHergic neurons are located, strongly suppresses REM sleep (Lin et al., 1989).

\section{Hypocretinergic neurons}

$\mathrm{MCH}$ inhibits waking-related hypocretinergic neurons (Rao et al., 2008), and by this means the MCHergic system may facilitate SWS and REM sleep. In fact, sleep attacks, sleep onset REM, and the intrusion of REM sleep-like atonia during wakefulness (cataplexy) characterize narcolepsy, where there is a suppression of the hypocretinergic activity due to a degeneration of the hypocretinergic neurons (Guilleminault and Fromherz, 2005; Mignot, 2005).

\section{Serotonergic neurons}

Serotonergic neurons of the DR are active during wakefulness, reduce their discharge during SWS, and are essentially silent during REM sleep (REM-off neurons; Jacobs and Azmitia, 1992). Furthermore, serotonin release decreases during REM sleep in diverse brain areas (Portas et al., 2000). Application of 5- $\mathrm{HT}_{\mathrm{A}}$ receptor agonists into the DR facilitates REM sleep occurrence, an effect mediated by the activation of inhibitory somatodendritic 5-HT1 $1_{\mathrm{A}}$ autoreceptors (Portas et al., 1996; Monti et al., 2002). The inhibition of serotonergic neurons of the DR following the microinjection of the $\mathrm{GABA}_{\mathrm{A}}$ agonist muscimol also increases REM sleep time (Nitz and Siegel, 1997). This outcome is similar to the one obtained following intra-DR microinjections of MCH (Lagos et al., 2009). In preliminary studies, microinjection of $\mathrm{MCH}$ into the DR of the cat produced similar effects (Devera et al., 2007).

Based upon the wake-related discharge pattern of serotonergic neurons it has been suggested that these neurons promote also wakefulness; in fact, there is strong evidence that the serotonergic neurons of the DR have a key role in the activation of the EEG (Dringenberg and Vanderwolf, 1998).

Therefore, it is likely that the microinjection of $\mathrm{MCH}$ into the DR inhibits the serotonergic neurons and by doing so, reduces wakefulness and increases REM sleep.

\section{GABAergic neurons of the NPO}

Due to the postulated inhibitory actions of $\mathrm{MCH}$, we believe that in order to facilitate the generation of REM sleep, $\mathrm{MCH}$ must inhibit the GABAergic "wake-ON" neurons in the NPO, thus allowing the activation of "REM sleep-ON" neurons (Xi et al., 1999; Luppi et al., 2007; Brown et al., 2008).

\section{Other waking-related neurons}

MCHergic neurons project also to other neural structures involved in the control of sleep and wakefulness including the basal forebrain, the tubero-mammillar nucleus of the hypothalamus, the
LDT-PPT, the LC, and the ventrolateral periaqueductal gray (vlPAG). Interestingly, the bilateral inhibition or lesions of the vlPAG and nearby areas generates an important increase in REM sleep amount (Sastre et al., 1996; Vanini et al., 2007; Kaur et al., 2009); therefore it is expected that MCH would promote REM sleep when applied onto this region (Peyron et al., 2009). We believe that MCH promotes sleep (both SWS and REM) acting not only on the vlPAG, but acting in tandem onto several waking and sleep-related regions.

MCHergic neurons innervate also the specific and non-specific nuclei of the thalamus, including the reticular nucleus (Bittencourt et al., 1992). By actions onto these nuclei as well as onto the neocortex, the MCHergic neurons could influence the EEG rhythms and behavioral states (Steriade, 2005).

\section{PHYSIOLOGICAL CONSIDERATIONS}

Energy conservation and restoration is one of the probable functions of sleep (Benington and Heller, 1995). Thus MCH would have an integrative role in energy conservation by promoting food intake, decreasing metabolism, and inducing sleep.

$\mathrm{MCH}$ decreases temperature, heart rate, and metabolic rate by central actions that enhance the parasympathetic/sympathetic tone ratio and decrease the release of thyroid hormones. Somatomotor activity is also reduced by $\mathrm{MCH}$ (Saito and Nagasaki, 2008). Given the profile of the activity of the MCHergic neurons it is possible that these actions are maximally expressed during sleep.

In order to conserve energy, MCHergic neurons could be involved also in the promotion of sleep in accordance with metabolic demands. It is likely that in conditions of energy abundance such as post-feeding time, $\mathrm{MCH}$ would first decrease the level of wakefulness, and then induce sleep. Furthermore, in special cases when energy conservation is imperative, MCHergic system may play a critical role. One case is hibernation, where the whole body metabolism falls to $1-2 \%$ of the basal value, and the body temperature could reach the freezing point of water (Heller and Ruby, 2004). Interestingly, the entrance to this state is through SWS.

Another paradigmatic physiological state is lactation, where we hypothesize that the activity of the MCHergic system would be very high. In fact, during this condition $\mathrm{MCH}$ is expressed in neurons of the medial preoptic area, a critical region for reproductive control and maternal behavior (Rondini et al., 2010). During the lactating period in the rat, the animals appear somnolent and the EEG is synchronized before milk ejection (Lincoln et al., 1980). Lactation is also associated with an increase in SWS in women (Blyton et al., 2002). Furthermore, it has been reported an increase in the amount of REM sleep after delivery (Petre-Quadens and De Lee, 1974). These authors also showed a gradual decrease in REM sleep in bottle-feeding mothers compared to breastfeeding mothers where REM sleep values remain high. Therefore, it would be important to investigate if the cause of this hypersomnia during lactation is promoted by $\mathrm{MCH}$.

On the other hand, depression of the MCHergic neuronal activity may mediate the effect of long-term sleep deprivation. This condition leads to a marked increase in energy expenditure and body weight loss (Rechtschaffen and Bergmann, 2002). In fact, this syndrome partly recalls the effect of the deletion of the $\mathrm{MCH}$ gene. 


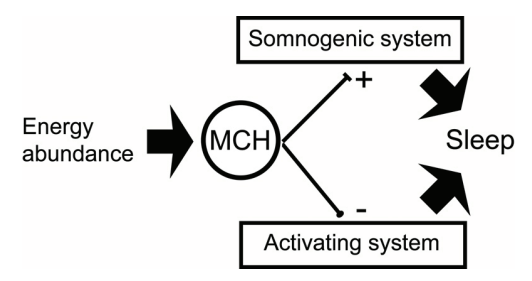

FIGURE 4 | The schematic shows a simple structural model that proposes a tentative mechanism by which $\mathrm{MCH}$ promotes sleep. During wakefulness MCHergic neurons may be activated during special conditions such as energy abundance. Inhibiting and facilitating the activating and somonogenic (SWS and REM sleep neuronal networks) respectively, $\mathrm{MCH}$ would facilitate and maintain sleep.

\section{MCH IN SLEEP: WORKING HYPOTHESIS}

Recently, Peyron et al. (2009) suggested that the MCHergic neurons are inhibited during wakefulness by extrahypothalamic waking-related neurons, and during SWS are inhibited by GABAergic neurons of the sleep-promoting preoptic region. On the other hand, glutamatergic REM sleep "ON” neurons of the sublaterodorsal nucleus would drive the MCHergic neurons. Thus, according to this proposal the MCHergic neurons are inhibited or driven by the classical activating or sleep-promoting system.

A complementary view is to consider that MCHergic neurons play a more active role in the induction of sleep; in other words, these neurons would drive the sleep-promoting regions instead of being driven by them. In addition, MCHergic neurons would inhibit the activating systems and promote sleep. A simple model is presented in Figure 4.

\section{THE MCHergic SYSTEM IN PATHOLOGY}

In spite of the large number of preclinical studies, there are almost no data regarding the pathophysiology of the MCHergic system.

Preclinical studies have demonstrated that $\mathrm{MCH}$ is related to energy homeostasis and it has been suggested that a dysfunction of this system could lead to obesity. In fact, there is one study that reports a trend toward association of several MCHR1 single-nucleotide polymorphisms with an obese phenotype in independent study groups of obese German children and adolescents (Wermter et al., 2005). Furthermore, MCHR1 antagonists could be a therapeutic option for treating obesity (Rivera et al., 2008).

Kokkotou et al. (2008) demonstrated that mice genetically deficient in $\mathrm{MCH}$ have substantially reduced local inflammatory responses in a model of experimental colitis. Likewise, mice receiving treatments with an anti-MCH antibody developed attenuated colonic inflammation and survived longer. Furthermore, there is an increased colonic expression of $\mathrm{MCH}$ and its receptor in

\section{REFERENCES}

Adamantidis, A., Salvert, D., Goutagny, R., Lakaye, B., Gervasoni, D., Grisar, T., Luppi, P. H., and Fort, P. (2008). Sleep architecture of the melaninconcentrating hormone receptor 1knockout mice. Eur. J. Neurosci. 27, 1793-1800.
Adrien, J. (2002). Neurobiological bases for the relation between sleep and depression. Sleep Med. Rev. 6, 341-351.

Ahnaou, A., Drinkenburg, W. H., Bouwknecht, J. A., Alcazar, J., Steckler, T., andDautzenberg,F.M.(2008).Blockingmelanin-concentrating hormone

patients with inflammatory bowel disease, suggesting a role of $\mathrm{MCH}$ in inflammatory processes in the intestine (Kokkotou et al., 2008).

We have mentioned earlier that there is preclinical evidence to support an increase in MCHergic activity in depression and that the antagonism of this system has antidepressant effects (Borowsky et al., 2002; Lagos et al., 2011b). In addition to pro-depressive effects, $\mathrm{MCH}$ promotes the occurrence of REM sleep in laboratory animals. Interestingly, in patients with a diagnosis of major depression (where there would be an increase in MCHergic tone), REM sleep occurrence is increased (Adrien, 2002). Accordingly, it could be of interest to determine the role of $\mathrm{MCH}$ in patients with depressive disorder.

Postpartum emotional distress or "blues" occurs in about 75$80 \%$ of new mothers about $3-5$ days after birth (Lee, 1998). This "blues" is typically confined to the 1 st week postpartum. More serious forms of maternal depression and postpartum psychosis occur in less than $10 \%$ of new mothers. Regarding the probable increment in activity of the MCHergic neurons during postpartum and lactation, it would be important to investigate if $\mathrm{MCH}$ is related to these emotional distresses.

As above-mentioned, there is a close anatomical and functional relationship between hypocretinergic and MCHergic neurons. Therefore, it is imperative to know how MCHergic neurons function in narcolepsy, where there is a degeneration of the hypocretinergic neurons; in fact, the malfunction of MCHergic neurons could play a role in the pathophysiology of this disease.

Parkinson's disease (PD) but not Huntington's disease, is accompanied by decrease in the number of MCHergic neurons (Thannickal et al., 2007; Aziz et al., 2008). The tentative relationship between a loss of MCHergic activity and some symptoms of PD has not been studied yet; however, a decrease in the activity of MCHergic cells could partly explain the high incidence of the REM sleep behavior disorder in this pathology (Thorpy and Adler, 2005).

\section{CONCLUSIONS AND FUTURE DIRECTIONS}

MCHergic neurons constitute a powerful regulatory system with wide and divergent projection. $\mathrm{MCH}$ is involved in the central regulation of food intake, energy balance, and mood. Recent evidence strongly suggests that $\mathrm{MCH}$ has a regulatory role in the control of sleep, mainly REM sleep. New experimental approaches are needed to unravel the role of $\mathrm{MCH}$ in sleep. Clinical research is also needed in order to determine the involvement of this peptide in a number of neuropsychiatric conditions.

\section{ACKNOWLEDGMENTS}

We are very grateful to the reviewers for their comments and suggestions that have improved the quality of our report.

$\mathrm{MCH}(1)$ receptor affects rat sleepwake architecture. Eur. J. Pharmacol. 579, 177-188.

Alon, T., and Friedman, J. M. (2006). Late-onset leanness in mice with targeted ablation of melanin concentrating hormone neurons. J. Neurosci. 26, 389-397.
Astrand, A., Bohlooly, Y. M., Larsdotter, S., Mahlapuu, M., Andersen, H., Tornell, J., Ohlsson, C., Snaith, M., and Morgan, D. G. (2004). Mice lacking melanin-concentrating hormone receptor 1 demonstrate increased heart rate associated with altered autonomic activity. Am. J. 
Physiol. Regul. Integr. Comp. Physiol. 287, R749-R758.

Aziz, A., Fronczek, R., Maat-Schieman, M., Unmehopa, U., Roelandse, F., Overeem, S., van Duinen, S., Lammers, G. J., Swaab, D., and Roos, R. (2008). Hypocretin and melaninconcentrating hormone in patients with Huntington disease. Brain Pathol. 18, 474-483.

Bachner, D., Kreienkamp, H., Weise, C., Buck, F., and Richter, D. (1999). Identification of melanin concentrating hormone $(\mathrm{MCH})$ as the natural ligand for the orphan somatostatin-like receptor 1 (SLC1). FEBS Lett. 457, 522-524.

Backberg, M., Hervieu, G., Wilson, S., and Meister, B. (2002). Orexin receptor-1 (OX-R1) immunoreactivity in chemically identified neurons of the hypothalamus: focus on orexin targets involved in control of food and water intake. Eur. J. Neurosci. 15, 315-328.

Baghdoyan, H. A., Rodrigo-Angulo, M. L., McCarley, R. W., and Hobson, J. A. (1987). A neuroanatomical gradient in the pontine tegmentum for the cholinoceptive induction of desynchronized sleep signs. Brain Res. 414, 245-261.

Bayer, L., Eggermann, E., Serafin, M., Grivel, J., Machard, D., Muhlethaler, M., and Jones, B. E. (2005). Opposite effects of noradrenaline and acetylcholine upon hypocretin/orexin versus melanin concentrating hormone neurons in rat hypothalamic slices. Neuroscience 130, 807-811.

Bayer, L., Mairet-Coello, G., Risold, P. Y., and Griffond, B. (2002). Orexin/hypocretin neurons: chemical phenotype and possible interactions with melanin-concentrating hormone neurons. Regul. Pept. 104, 33-39.

Benington, J. H., and Heller, H. C. (1995). Restoration of brain energy metabolism as the function of sleep. Prog. Neurobiol. 45, 347-360.

Bernardis, L. L., and Bellinger, L. L. (1996). The lateral hypothalamic area revisited: ingestive behavior. Neurosci. Biobehav. Rev. 20, 189-287.

Bittencourt, J., and Celis, M. E. (2008). Anatomy, function and regulation of neuropeptide EI (NEI). Peptides 29, 1441-1450.

Bittencourt, J. C., Presse, F., Arias, C., Peto, C., Vaughan, J., Nahon, J. L., Vale, W., and Sawchenko, P. E. (1992). The melanin-concentrating hormone system of the rat brain: an immuno- and hybridization histochemical characterization. J. Comp. Neurol. 319, 218-245.

Blyton, D. M., Sullivan, C. E., and Edwards, N. (2002). Lactation is associated with an increase in slowwave sleep in women. J. Sleep Res. 11, 297-303.

Borowsky, B., Durkin, M. M., Ogozalek, K., Marzabadi, M. R., DeLeon, J., Heurich, R., Lichtblau, H., Shaposhnik, Z., Daniewska, I., Blackburn, T. P., Branchek, T. A., Gerald, C., Vaysse, P. J., and Forray, C. (2002). Antidepressant, anxiolytic and anorectic effects of a melaninconcentrating hormone-1 receptor antagonist. Nat. Med. 8, 825-830.

Borsu, L., Presse, F., and Nahon, J. L. (2000). The AROM gene, spliced mRNAs encoding new DNA/RNAbinding proteins are transcribed from the opposite strand of the melanin-concentrating hormone gene in mammals. J. Biol. Chem. 275, 40576-40587.

Brown, R. E., McKenna, J. T., Winston, S., Basheer, R., Yanagawa, Y., Thakkar, M. M., and McCarley, R. W. (2008). Characterization of GABAergic neurons in rapid-eyemovement sleep controlling regions of the brainstem reticular formation in GAD67-green fluorescent protein knock-in mice. Eur. J. Neurosci. 27, 352-363.

Burdakov, D., Gerasimenko, O., and Verkhratsky, A. (2005). Physiological changes in glucose differentially modulate the excitability of hypothalamic melanin-concentrating hormone and orexin neurons in situ. J. Neurosci. 25, 2429-2433.

Chaki, S., Funakoshi, T., HirotaOkuno, S., Nishiguchi, M., Shimazaki, T., Iijima, M., Grottick, A. J., Kanuma, K., Omodera, K., Sekiguchi, Y., Okuyama, S., Tran, T. A., Semple, G., and Thomsen, W. (2005). Anxiolyticand antidepressant-like profile of ATC0065 and ATC0175: nonpeptidic and orally active melaninconcentrating hormone receptor 1 antagonists. J. Pharmacol. Exp. Ther $313,831-839$.

Chambers, J., Ames, R. S., Bergsma, D., Muir, A., Fitzgerald, L. R., Hervieu, G., Dytko, G. M., Foley, J. J., Martin, J., Liu, W. S., Park, J., Ellis, C., Ganguly, S., Konchar, S., Cluderay, J., Leslie, R., Wilson, S., and Sarau, H. M. (1999). Melanin-concentrating hormone is the cognate ligand for the orphan G-protein-coupled receptor SLC-1. Nature 400, 261-265.

Chase, M., and Morales, F. R. (2005). "Control of motoneurons during sleep," in Principles and Practices of Sleep Medicine, eds M. H. Kryger, T. Roth and W. C. Dement (Philadelphia: Elsevier-Saunders), 154-168.
Chung, S., Saito, Y., and Civelli, O. (2009). MCH receptors/gene structure-in vivo expression. Peptides 30, 1985-1989.

Devera, A., Lagos, P., Chase, M., and Torterolo, P. (2007). MCH en el núcleo dorsal del rafe: rol en la vigilia y el sueño. Actas Fisiol. 11, 129.

Dringenberg, H. C., and Vanderwolf, C. H. (1998). Involvement of direct and indirect pathways in electrocorticographic activation. Neurosci. Biobehav. Rev. 22, 243-257.

Elias, C. F., Lee, C. E., Kelly, J. F., Ahima, R. S., Kuhar, M., Saper, C. B., and Elmquist, J. K. (2001). Characterization of CART neurons in the rat and human hypothalamus. J. Comp. Neurol. 432, 1-19.

Elias, C. F., Sita, L. V., Zambon, B. K., Oliveira, E. R., Vasconcelos, L. A., and Bittencourt, J. C. (2008). Melanin-concentrating hormone projections to areas involved in somatomotor responses. J. Chem. Neuroanat. 35, 188-201.

Fort, P., Salvert, D., Hanriot, L., Jego, S., Shimizu, H., Hashimoto, K., Mori, M., and Luppi, P. H. (2008). The satiety molecule nesfatin- 1 is coexpressed with melanin concentrating hormone in tuberal hypothalamic neurons of the rat. Neuroscience $155,174-181$.

Fuller, P. M., Saper, C. B., and Lu, J. (2007). The pontine REM switch: past and present. J. Physiol. 584, 735-741.

Gao, X. B., and van den Pol, A. N. (2001). Melanin concentrating hormone depresses synaptic activity of glutamate and GABA neurons from rat lateral hypothalamus. J. Physiol. 533, 237-252.

Gao, X. B., and van den Pol, A. N. (2002). Melanin-concentrating hormone depresses L-, $\mathrm{N}$-, and P/Q-type voltage-dependent calcium channels in rat lateral hypothalamic neurons. J. Physiol. 542, 273-286.

Goutagny, R., Luppi, P. H., Salvert, D. Gervasoni, D., and Fort, P. (2005). GABAergic control of hypothalamic melanin-concentrating hormonecontaining neurons across the sleep-waking cycle. Neuroreport 16, 1069-1073.

Guan, J. L., Uehara, K., Lu, S., Wang, Q. P., Funahashi, H., Sakurai, T., Yanagisawa, M., and Shioda, S. (2002). Reciprocal synaptic relationship between orexin-and melaninconcentrating hormone-containing neurons in the rat lateral hypothalamus: a novel circuit implicated in feeding regulation. Int J. Obes. Relat. Metab. Disord. 26, 1523-1532.
Guilleminault, C., and Fromherz, S. (2005). "Narcolepsy: diagnosis and management," in Principles and Practices of Sleep Medicine, eds M. H. Kryger, T. Roth and W. C. Dement (Philadelphia: Saunders), 780-790.

Guyon, A., Conductier, G., Rovere, C., Enfissi, A., and Nahon, J. L. (2009). Melanin-concentrating hormone producing neurons: activities and modulations. Peptides 30, 2031-2039.

Hanriot, L., Camargo, N., Courau, A. C., Leger, L., Luppi, P. H., and Peyron, C. (2007). Characterization of the melanin-concentrating hormone neurons activated during paradoxical sleep hypersomnia in rats. J. Comp. Neurol. 505, 147-157.

Harthoorn, L. F., Sane, A., Nethe, M., and Van Heerikhuize, J. J. (2005). Multi-transcriptional profiling of melanin-concentrating hormone and orexin-containing neurons Cell. Mol. Neurobiol. 25, 1209-1223.

Hassani, O. K., Lee, M. G., and Jones, B. E. (2009). Melanin-concentrating hormone neurons discharge in a reciprocal manner to orexin neurons across the sleep-wake cycle. Proc. Natl. Acad. Sci. U.S.A. 106, 2418-2422.

Hawes, B. E., Kil, E., Green, B., O’Neill, K., Fried, S., and Graziano, M. P. (2000). The melanin-concentrating hormone receptor couples to multiple $\mathrm{G}$ proteins to activate diverse intracellular signaling pathways. Endocrinology 141, 4524-4532.

Heller, H. C., and Ruby, N. F. (2004). Sleep and circadian rhythms in mammalian torpor. Annu. Rev. Physiol. 66, 275-289.

Hill, J., Duckworth, M., Murdock, P., Rennie, G., Sabido-David, C., Ames, R. S., Szekeres, P., Wilson, S., Bergsma, D. J., Gloger, I. S., Levy, D. S., Chambers, J. K., and Muir, A. I. (2001). Molecular cloning and functional characterization of $\mathrm{MCH} 2$, a novel human MCH receptor. J. Biol. Chem. 276, 20125-20129.

Huang, H., Acuna-Goycolea, C., Li, Y., Cheng, H. M., Obrietan, K., and van den Pol, A. N. (2007). Cannabinoids excite hypothalamic melaninconcentrating hormone but inhibit hypocretin/orexin neurons: implications for cannabinoid actions on food intake and cognitive arousal. $J$. Neurosci. 27, 4870-4881.

Huang, H., and van den Pol, A. N. (2007). Rapid direct excitation and long-lasting enhancement of NMDA response by group I metabotropic glutamate receptor activation of hypothalamic melanin- 
concentrating hormone neurons. J. Neurosci. 27, 11560-11572.

Jacobs, B. L., and Azmitia, E. C. (1992). Structure and function of the brain serotonin system. Physiol. Rev. 72, $165-229$.

Jones, B. (2005). "Basic mechanisms of sleep-wake states," in Principles and Practices of Sleep Medicine, eds M. H. Kryger, T. Roth and W. C. Dement (Philadelphia: ElsevierSaunders), 136-153.

Kaur, S., Thankachan, S., Begum, S., Liu, M., Blanco-Centurion, C., and Shiromani, P. J. (2009). Hypocretin2 saporin lesions of the ventrolateral periaquaductal gray (vlPAG) increase REM sleep in hypocretin knockout mice. PLoS ONE 4, e6346. doi: 10.1371/journal.pone.0006346

Kawauchi, H., Kawazoe, I., Tsubokawa, M., Kishida, M., and Baker, B. I. (1983). Characterization of melanin-concentrating hormone in chum salmon pituitaries. Nature 305, 321-323.

Kokkotou, E., Moss, A. C., Torres, D., Karagiannides, I., Cheifetz, A., Liu, S., O’Brien, M., Maratos-Flier, E., and Pothoulakis, C. (2008). Melanin-concentrating hormone as a mediator of intestinal inflammation. Proc. Natl. Acad. Sci. U.S.A. 105, 10613-10618.

Lagos, P., Torterolo, P., Jantos, H., Chase, M. H., and Monti, J. M. (2009). Effects on sleep of melaninconcentrating hormone microinjections into the dorsal raphe nucleus. Brain Res. 1265, 103-110.

Lagos, P., Torterolo, P., Jantos, H., Chase, M. H., and Monti, J. M. (2011a). Immunoneutralization of melaninconcentrating hormone $(\mathrm{MCH})$ in the dorsal raphe nucleus: effects on sleep and wakefulness. Brain Res. 1269, 112-118.

Lagos, P., Urbanavicius, J., Scorza, C., Miraballes, R., and Torterolo, P. (2011b). Depressive-like profile induced by $\mathrm{MCH}$ microinjections into the dorsal raphe nucleus evaluated in the forced swim test. Behav. Brain Res. 218, 259-266.

Lakaye, B., Coumans, B., Harray, S., and Grisar, T. (2009). Melaninconcentrating hormone and immune function. Peptides 30, 2076-2080.

Lee, K. A. (1998). Alterations in sleep during pregnancy and postpartum: a review of 30 years of research. Sleep Med. Rev. 2, 231-242.

Lee, M. G., Hassani, O. K., and Jones, B. E. (2005). Discharge of identified orexin/hypocretin neurons across the sleep-waking cycle. J. Neurosci. 25, 6716-6720.
Lembo, P. M., Grazzini, E., Cao, J., Hubatsch, D. A., Pelletier, M., Hoffert, C., St-Onge, S., Pou, C., Labrecque, J., Groblewski, T., O’Donnell, D., Payza, K., Ahmad, S., and Walker, P. (1999). The receptor for the orexigenic peptide melaninconcentrating hormone is a Gprotein-coupled receptor. Nat. Cell Biol. 1, 267-271.

Lin, J. S., Sakai, K., Vanni-Mercier, G. and Jouvet, M. (1989). A critical role of the posterior hypothalamus in the mechanisms of wakefulness determined by microinjection of muscimol in freely moving cats. Brain Res. 479, 225-240.

Lincoln, D. W., Hentzen, K., Hin, T. van der Schoot, P., Clarke, G., and Summerlee, A. J. (1980). Sleep: a prerequisite for reflex milk ejection in the rat. Exp. Brain Res. 38, 151-162.

Ludwig, D. S., Tritos, N. A., Mastaitis, J. W., Kulkarni, R., Kokkotou, E., Elmquist, J., Lowell, B., Flier, J. S., and Maratos-Flier, E. (2001). Melaninconcentrating hormone overexpression in transgenic mice leads to obesity and insulin resistance. J. Clin. Invest. 107, 379-386.

Luppi, P. H., Gervasoni, D., Verret, L., Goutagny, R., Peyron, C., Salvert, D., Leger, L., and Fort, P. (2007). Paradoxical (REM) sleep genesis: the switch from an aminergic-cholinergic to a GABAergic-glutamatergic hypothesis. J. Physiol. Paris 100, 271-283.

Marsh, D. J., Weingarth, D. T., Novi, D. E., Chen, H. Y., Trumbauer, M. E., Chen, A. S., Guan, X. M., Jiang, M. M., Feng, Y., Camacho, R. E., Shen, Z., Frazier, E. G., Yu, H., Metzger, J. M., Kuca, S. J., Shearman, L. P., Gopal-Truter, S., MacNeil, D. J., Strack, A. M., MacIntyre, D. E., Van der Ploeg, L. H., and Qian, S. (2002). Melaninconcentrating hormone 1 receptordeficient mice are lean, hyperactive, and hyperphagic and have altered metabolism. Proc. Natl. Acad. Sci. U.S.A. 99, 3240-3245.

McCarley, R. W. (2007). Neurobiology of REM and NREM sleep. Sleep Med. 8, 302-330.

McGregor, R., Damian, A., Fabbiani, G., Torterolo, P., Pose, I., Chase, M., and Morales, F. R. (2005). Direct hypothalamic innervation of the trigeminal motor nucleus: a retrograde tracer study. Neuroscience 136, 1073-1081.

Mignot, E. (2005). "Narcolepsy: pharmacology, pathophysiology and genetics," in Principles and
Practices of Sleep Medicine, eds M. H. Kryger, T. Roth and W. C. Dement (Philadelphia: Saunders), 761-799.

Mileykovskiy, B. Y., Kiyashchenko, L. I., and Siegel, J. M. (2005). Behavioral correlates of activity in identified hypocretin/orexin neurons. Neuron 46, 787-798.

Modirrousta, M., Mainville, L., and Jones, B. E. (2005). Orexin and $\mathrm{MCH}$ neurons express c-Fos differently after sleep deprivation vs. recovery and bear different adrenergic receptors. Eur. J. Neurosci. 21, 2807-2816.

Monti, J. M. (2010a). The role of dorsal raphe nucleus serotonergic and nonserotonergic neurons, and of their receptors, in regulating waking and rapid eye movement (REM) sleep. Sleep Med. Rev. 14, 319-327.

Monti, J. M. (2010b). The structure of the dorsal raphe nucleus and its relevance to the regulation of sleep and wakefulness. Sleep Med. Rev. 14 307-317.

Monti, J. M., and Jantos, H. (2008). The roles of dopamine and serotonin, and of their receptors, in regulating sleep and waking. Prog. Brain Res. 172, 625-646.

Monti, J. M., Jantos, H., and Monti, D. (2002). Increased REM sleep after intra-dorsal raphe nucleus injection of flesinoxan or 8-OHDPAT: prevention with WAY 100635 Eur. Neuropsychopharmacol. 12 47-55.

Mori, M., Harada, M., Terao, Y., Sugo, T., Watanabe, T., Shimomura, Y., Abe, M., Shintani, Y., Onda, H., Nishimura, O., and Fujino, M. (2001). Cloning of a novel G protein-coupled receptor, SLT, a subtype of the melanin-concentrating hormone receptor. Biochem. Biophys. Res. Commun. 283 1013-1018.

Mouri, T., Takahashi, K., Kawauchi, H. Sone, M., Totsune, K., Murakami, O., Itoi, K., Ohneda, M., Sasano, H., and Sasano, N. (1993). Melanin-concentrating hormone in the human brain. Peptides 14, 643-646.

Murillo-Rodriguez, E. (2008). The role of the CB1 receptor in the regulation of sleep. Prog. Neuropsychopharmacol. Biol. Psychiatry 32, 1420-1427.

Nishino, S., Ripley, B., Overeem, S. Lammers, G. J., and Mignot, E. (2000). Hypocretin (orexin) deficiency in human narcolepsy. Lancet 355, 39-40.

Nitz, D., and Siegel, J. (1997). GABA release in the dorsal raphe nucleus: role in the control of REM sleep. Am J. Physiol. 273, R451-R455.

Petre-Quadens, O., and De Lee, C. (1974). "Sleep-cycle alterations during pregnancy, postpartum and the menstrual cycle," in Biorhythms and Human Reproduction, eds M. Ferin, F. Halberg and R. M. Richart (New York: John Wiley), 335-351.

Peyron, C., Faraco, J., Rogers, W., Ripley, B., Overeem, S., Charnay, Y., Nevsimalova, S., Aldrich, M., Reynolds, D., Albin, R., Li, R., Hungs, M., Pedrazzoli, M., Padigaru, M., Kucherlapati, M., Fan, J., Maki, R., Lammers, G. J., Bouras, C., Kucherlapati, R., Nishino, S., and Mignot, E. (2000). A mutation in a case of early onset narcolepsy and a generalized absence of hypocretin peptides in human narcoleptic brains. Nat. Med. 6 , 991-997.

Peyron, C., Sapin, E., Leger, L., Luppi, P. H., and Fort, P. (2009). Role of the melanin-concentrating hormone neuropeptide in sleep regulation. Peptides 30, 2052-2059.

Portas, C. M., Bjorvatn, B., and Ursin, R. (2000). Serotonin and the sleep/wake cycle: special emphasis on microdialysis studies. Prog. Neurobiol. 60, 13-35.

Portas, C. M., Thakkar, M., Rainnie, D., and McCarley, R. W. (1996). Microdialysis perfusion of 8-hydroxy-2-(di$\mathrm{N}$-propylamino)tetralin $\quad(8-\mathrm{OH}-$ DPAT) in the dorsal raphe nucleus decreases serotonin release and increases rapid eye movement sleep in the freely moving cat. J. Neurosci. 16, 2820-2828.

Qu, D., Ludwig, D. S., Gammeltoft, S., Piper, M., Pelleymounter, M. A., Cullen, M. J., Mathes, W. F., Przypek, R., Kanarek, R., and Maratos-Flier, E. (1996). A role for melanin-concentrating hormone in the central regulation of feeding behaviour. Nature 380 243-247.

Quintela, H., Lagos, P., Alzugaray, S., Torterolo, P., and Ungerfeld, R. (2010). "Changes on melanin-concentration hormone cerebrospinal fluid concentration in anoestrous ewes in response to the ram effect," in Proceedings of the The 8th International Ruminant Reproduction Symposium, Anchorage, AL.

Rao, Y., Lu, M., Ge, F., Marsh, D. J., Qian, S., Wang, A. H., Picciotto, M. R., and Gao, X. B. (2008). Regulation of synaptic efficacy in hypocretin/orexincontaining neurons by melanin 
concentrating hormone in the lateral hypothalamus. J. Neurosci. 28, 9101-9110.

Rechtschaffen, A., and Bergmann, B. M. (2002). Sleep deprivation in the rat: an update of the 1989 paper. Sleep $25,18-24$.

Reinoso-Suarez, F., de Andres, I., Rodrigo-Angulo, M. L., and Garzon, M. (2001). Brain structures and mechanisms involved in the generation of REM sleep. Sleep Med. Rev. 5, 63-77.

Rivera, G., Bocanegra-Garcia, V., Galiano, S., Cirauqui, N., Ceras, J., Perez, S., Aldana, I., and Monge, A. (2008). Melanin-concentrating hormone receptor 1 antagonists: a new perspective for the pharmacologic treatment of obesity. Curr. Med. Chem. 15, 1025-1043.

Rodriguez, E. M., Blazquez, J. L., Pastor, F. E., Pelaez, B., Pena, P., Peruzzo, B., and Amat, P. (2005). Hypothalamic tanycytes: a key component of brain-endocrine interaction. Int. Rev. Cytol. 247, 89-164.

Rondini, T. A., de Crudis Rodrigues, B., de Oliveira, A. P., Bittencourt, J. C., and Elias, C. F. (2007). Melaninconcentrating hormone is expressed in the laterodorsal tegmental nucleus only in female rats. Brain Res. Bull. 74, 21-28.

Rondini, T. A., Donato, J. Jr., Rodrigues Bde, C., Bittencourt, J. C., and Elias, C. F. (2010). Chemical identity and connections of medial preoptic area neurons expressing melaninconcentrating hormone during lactation. J. Chem. Neuroanat. 39, 51-62.

Sailer, A. W., Sano, H., Zeng, Z., McDonald, T. P., Pan, J., Pong, S. S., Feighner, S. D., Tan, C. P., Fukami, T., Iwaasa, H., Hreniuk, D. L., Morin, N. R., Sadowski, S. J., Ito, M., Bansal, A., Ky, B., Figueroa, D. J., Jiang, Q., Austin, C. P., MacNeil, D. J., Ishihara, A., Ihara, M., Kanatani, A., Van der Ploeg, L. H., Howard, A. D., and Liu, Q. (2001). Identification and characterization of a second melanin-concentrating hormone receptor, MCH-2R. Proc. Natl. Acad. Sci. U.S.A. 98, 7564-7569.

Saito, Y., and Nagasaki, H. (2008). The melanin-concentrating hormone system and its physiological functions. Results Probl. Cell Differ. 46, 159-179.

Sapin, E., Berod, A., Leger, L., Herman, P. A., Luppi, P. H., and Peyron,
C. (2010). A very large number of GABAergic neurons are activated in the tuberal hypothalamus during paradoxical (REM) sleep hypersomnia. PLoS ONE 5, el1766. doi 10.1371/journal.pone.0011766

Sastre, J. P., Buda, C., Kitahama, K., and Jouvet, M. (1996). Importance of the ventrolateral region of the periaqueductal gray and adjacent tegmentum in the control of paradoxical sleep as studied by muscimol microinjections in the cat. Neuroscience 74, 415-426.

Satoh, S., Matsumura, H., Kanbayashi, T., Yoshida, Y., Urakami, T., Nakajima, T., Kimura, N., Nishino, S., and Yoneda, H. (2006). Expression pattern of FOS in orexin neurons during sleep induced by an adenosine A2A receptor agonist. Behav. Brain Res. 170, 277-286.

Segal-Lieberman, G., Bradley, R. L., Kokkotou, E., Carlson, M., Trombly, D. J., Wang, X., Bates, S., Myers, M. G. Jr., Flier, J. S., and Maratos-Flier, E. (2003). Melanin-concentrating hormone is a critical mediator of the leptin-deficient phenotype. Proc. Natl. Acad. Sci. U.S.A. 100, 1008510090.

Shimada, M., Tritos, N. A., Lowell, B. B., Flier, J. S., and Maratos-Flier, E. (1998). Mice lacking melanin-concentrating hormone are hypophagic and lean. Nature 396, 670-674.

Shimomura, Y., Mori, M., Sugo, T., Ishibashi, Y., Abe, M., Kurokawa, T., Onda, H., Nishimura, O., Sumino, Y., and Fujino, M. (1999). Isolation and identification of melanin-concentrating hormone as the endogenous ligand of the SLC-1 receptor. Biochem. Biophys. Res. Commun. 261, 622-626.

Siegel, J. M. (2005). "REM sleep," in Principles and Practices of Sleep Medicine, eds M. H. Kryger, T. Roth and W. C. Dement (Philadelphia: Elsevier-Saunders), 120-135.

Skofitsch, G., Jacobowitz, D. M., and Zamir, N. (1985). Immunohistochemical localization of a melanin concentrating hormone-like peptide in the rat brain. Brain Res. Bull. 15, 635-649.

Steriade, M. (2005). "Brain electrical activity and sensory processing during waking and sleep states," in Principles and Practices of Sleep Medicine, eds M. H. Kryger, T. Roth and W. C. Dement (Philadelphia: Saunders), 101-119.

Szymusiak, R., and McGinty, D. (2008). Hypothalamic regulation of sleep and arousal. Ann. N. Y. Acad. Sci. 1129, 275-286.

Tan, C. P., Sano, H., Iwaasa, H., Pan, J., Sailer, A. W., Hreniuk, D. L., Feighner, S. D., Palyha, O. C., Pong, S. S., Figueroa, D. J., Austin, C. P., Jiang, M. M., Yu, H., Ito, J., Ito, M., Guan, X. M., MacNeil, D. J., Kanatani, A., Van der Ploeg, L. H., and Howard, A. D. (2002). Melanin-concentrating hormone receptor subtypes 1 and 2: species-specific gene expression. Genomics 79, 785-792.

Thannickal, T. C., Lai, Y. Y., and Siegel, J. M. (2007). Hypocretin (orexin) cell loss in Parkinson's disease. Brain 130, 1586-1595.

Thannickal, T. C., Moore, R. Y., Nienhuis, R., Ramanathan, L., Gulyani, S., Aldrich, M., Cornford, M., and Siegel, J. M. (2000). Reduced number of hypocretin neurons in human narcolepsy. Neuron 27, 469-474.

Thorpy, M. J., and Adler, C. H. (2005). Parkinson's disease and sleep. Neurol. Clin. 23, 1187-1208.

Torterolo, P., Lagos, P., Sampogna, S. and Chase, M. H. (2008). Melaninconcentrating hormone $(\mathrm{MCH})$ immunoreactivity in non-neuronal cells within the raphe nuclei and subventricular region of the brainstem of the cat. Brain Res. 1210 , 163-178.

Torterolo, P., Rojas, M., Sampogna, S., Morales, F. R., and Chase, M. H. (2003a). MCH-containing neurons and the control of sleep and wakefulness. Sleep 26, A20.

Torterolo, P., Yamuy, J., Sampogna, S., Morales, F. R., and Chase, M. H. (2003b). Hypocretinergic neurons are primarily involved in activation of the somatomotor system. Sleep 1 , 25-28.

Torterolo, P., Sampogna, S., and Chase, M. H. (2009). MCHergic projections to the nucleus pontis oralis participate in the control of active (REM) sleep. Brain Res. 1268, 76-87.

Torterolo, P., Sampogna, S., Morales, F. R., and Chase, M. H. (2006). $\mathrm{MCH}$-containing neurons in the hypothalamus of the cat: searching for a role in the control of sleep and wakefulness. Brain Res. 1119, 101-114.

Torterolo, P., and Vanini, G. (2010). Nuevos conceptos sobre la generación y el mantenimiento de la vigilia. Rev. Neurol. 50, 747-758.

Torterolo, P., Yamuy, J., Sampogna, S., Morales, F. R., and Chase, M. H.
(2001). Hypothalamic neurons that contain hypocretin (orexin) express c-fos during active wakefulness and carbachol-induced active sleep. Sleep Res. Online 4, 25-32. Available at: http://www.sro.org/2001/ Torterolo/2025

Toumaniantz, G., Bittencourt, J. C., and Nahon, J. L. (1996). The rat melanin-concentrating hormone gene encodes an additional putative protein in a different reading frame. Endocrinology 137, 4518-4521.

van den Pol, A. N., Acuna-Goycolea, C., Clark, K. R., and Ghosh, P. K. (2004). Physiological properties of hypothalamic $\mathrm{MCH}$ neurons identified with selective expression of reporter gene after recombinant virus infection. Neuron 42, 635-652.

Vanini, G., Torterolo, P., McGregor, R., Chase, M. H., and Morales, F R. (2007). GABAergic processes in the mesencephalic tegmentum modulate the occurrence of active (rapid eye movement) sleep in guinea pigs. Neuroscience 145, 1157-1167.

Veening, J. G., and Barendregt, $\mathrm{H}$. P. (2010). The regulation of brain states by neuroactive substances distributed via the cerebrospinal fluid; a review. Cerebrospinal Fluid Res. 7,1 .

Veening, J. G., de Jong, T., and Barendregt, H. P. (2010). Oxytocinmessages via the cerebrospinal fluid: behavioral effects; a review. Physiol. Behav. 101, 193-210.

Verret, L., Goutagny, R., Fort, P., Cagnon, L., Salvert, D., Leger, L., Boissard, R., Salin, P., Peyron, C., and Luppi, P. H. (2003). A role of melanin-concentrating hormone producing neurons in the central regulation of paradoxical sleep. BMC Neurosci. 4, 19. doi: 10.1186/1471-2202-4-19

Wermter, A. K., Reichwald, K., Buch, T., Geller, F., Platzer, C., Huse, K., Hess, C., Remschmidt, H., Gudermann, T., Preibisch, G., Siegfried, W., Goldschmidt, H. P., Li, W. D., Price, R. A., Biebermann, H., Krude, H., Vollmert, C., Wichmann, H. E., Illig, T., Sorensen, T. I., Astrup, A., Larsen, L. H., Pedersen, O., Eberle, D., Clement, K., Blundell, J., Wabitsch, M., Schafer, H., Platzer, M., Hinney, A., and Hebebrand, J. (2005). Mutation analysis of the MCHR1 gene in human obesity. Eur. J. Endocrinol. 152, 851-862.

Willie, J. T., Sinton, C. M., MaratosFlier, E., and Yanagisawa, M. (2008). 
Abnormal response of melaninconcentrating hormone deficient mice to fasting: hyperactivity and rapid eye movement sleep suppression. Neuroscience 156, 819-829.

Willie, J. T., Sinton, C. M., Mieda, M., Maratos-Flier, E., and Yanagisawa, M. (2003). Orexin and melanin-concentrating hormone $(\mathrm{MCH})$ double knockout mice: compensatroy role for $\mathrm{MCH}$ in narcolepsy-cataplexy. Sleep 26, A50.

Wu, M., Dumalska, I., Morozova, E., van den Pol, A., and Alreja, M. (2009).
Melanin-concentrating hormone directly inhibits $\mathrm{GnRH}$ neurons and blocks kisspeptin activation, linking energy balance to reproduction. Proc. Natl. Acad. Sci. U.S.A. 106, 17217-17222.

Xi, M. C., Morales, F. R., and Chase, M. H. (1999). Evidence that wakefulness and REM sleep are controlled by a GABAergic pontine mechanism. J. Neurophysiol. 82, 2015-2019.

Xi, M. C., Morales, F. R., and Chase, M. H. (2001). Induction of wakefulness and inhibition of active (REM) sleep by GABAergic processes in the nucleus pontis oralis. Arch. Ital. Biol. 139, 125-145.

Conflict of Interest Statement: The authors declare that the research was conducted in the absence of any commercial or financial relationships that could be construed as a potential conflict of interest.

Received: 21 December 2010; accepted: 02 March 2011; published online: 18 March 2011.
Citation: Torterolo $P$, Lagos $P$ and Monti JM (2011) Melanin-concentrating hormone: a new sleep factor? Front. Neur. 2:14. doi: 10.3389/fneur.2011.00014

This article was submitted to Frontiers in Sleep and Chronobiology, a specialty of Frontiers in Neurology.

Copyright (c) 2011 Torterolo, Lagos and Monti. This is an open-access article subject to an exclusive license agreement between the authors and Frontiers Media $S A$, which permits unrestricted use, distribution, and reproduction in any medium, provided the original authors and source are credited. 